\title{
Current Strategies of Genomic Modification in Livestock and Applications in Poultry
}

\author{
Tae Sub Park* \\ Graduate School of International Agricultural Technology and Institute of Green-Bio Science and Technology, Seoul \\ National University, Pyeongchang 25354, Korea
}

Received June 6, 2019

Revised June 14, 2019

Accepted June 18, 2019

\section{*Correspondence}

Tae Sub Park

Graduate School of International Agricultural Technology, Seoul National University, Pyeongchang 25354, Korea

Tel: +82-33-339-5721

Fax: +82-33-339-5763

E-mail: taesubpark@snu.ac.kr ORCID

https://orcid.org/0000-0002-0372-5467

\begin{abstract}
Since the development of the first genetically-modified mouse, transgenic animals have been utilized for a wide range of industrial applications as well as basic research. To date, these transgenic animals have been used in functional genomics studies, disease models, and therapeutic protein production. Recent advances in genome modification techniques such zinc finger nuclease (ZFN), transcription activator-like effector nucleases (TALEN), and clustered regularly interspaced short palindromic repeats (CRIPSR)-Cas9, have led to rapid advancement in the generation of genome-tailored livestock, as well as experimental animals; however, the development of genome-edited poultry has shown considerably slower progress compared to that seen in mammals. Here, we will focus primarily on the technical strategies for production of transgenic and gene-edited chickens, and their potential for future applications.
\end{abstract}

Keywords: chicken, CRISPR/Cas9, genome-editing, transgenic

\section{GENOME MODIFICATION IN CHICKENS}

Birds have a distinguished history as a model system in the biosciences. Recent developments in genetic modification technologies, including the transposon-transposase and CRISPR/Cas9 systems, are expected to revolutionize genomic research when applied to avian species (Park et al., 2012; Park et al., 2019). Based on the methods of somatic cell nuclear transfer (SCNT) for animal cloning and direct injection into one-cell-stage embryo, numerous CRISPR/Cas9-mediated knockout and knock-in animals have been successfully generated, particularly in mammals (Cong et al., 2013; Mali et al., 2013); however, technical difficulties due to developmental and physiological differences between avian and mammalian species have significantly limited the use of these methods in avian species (Park and Han, 2012; Schusser et al., 2013; Park et al., 2014; Park et al., 2019).

A wide range of platforms have been used to develop transgenic or gene-edited mammals (Park et al., 2012), of which viral transduction remains the most promising delivery system, as these viral vectors are able to stably integrate the target gene into the host genome (Harvey et al., 2002; McGrew et al., 2004; Kamihira et al., 2005; Scott et al., 2006; Lillico et al., 2007). Similar attempts to transfer exogenous transgenes by viral transduction, including the use of retrovirus and lentivirus, have been used in poultry (Harvey et al., 2002; McGrew et al., 2004; Kamihira et al., 2005; Scott et al., 2006; Lillico et al., 2007); however, these approaches are not practical for industrial products due to transgene silencing and safety issues related to viral risk (Park and Han, 2012). Recently, a non-viral 
technical platform of transposon/transposase-mediated transgenesis such as piggyBac and the Tol2 system has been reported in chickens (Park and Han, 2012; Schusser et al., 2013). Park and Han (2014) reported that the enhanced green fluorescent protein (eGFP) transgene was stably inserted into chicken primordial germ cells (PGCs), the avian precursor of sperm or oocyte germ cells, by cotransfection with piggyBac eGFP transposon and transposase (Park and Han, 2012). Furthermore, the average germline transmission efficiency with piggyBac eGFP transposon-mediated PGCs was $95.2 \%$ in the germline chimeric founders (Park and Han, 2012), suggesting the possibility of a practical application for production of foreign therapeutic proteins from transgenic chickens.

The first knockout mouse was first developed over three decades ago using conventional homologous recombination methods (Koller et al., 1989; Thompson et al., 1989) however, it was not until 2013 that the generation of a knockout chicken was first reported (Schusser et al., 2013). Schusser et al. (2013) deleted the immunoglobulin (Ig) gene using a conventional homologous recombination approach in chicken PGCs, after which they were able to generate Ig knockout chickens from the germline chimeric founder following Ig-modified germ cell transplantation. The following year, Park et al. (2014) reported the creation of an ovalbumin gene knockout chicken using the TALEN gene-editing platform (Park et al., 2014). More recently, there have been a handful of reports describing the generation of targeted mutants in chicken via the CRISPR/Cas9 system (Dimitrov et al., 2016; Oishi et al., 2016; Oishi et al., 2018; Park et al, 2019).

In 2018, Oishi et al. generated a knock-in (KI) chicken in which the human interferon-beta (hIFN- $\beta$ ) gene was inserted into the ovalbumin gene mediated via CRISPR/ Cas9 (Oishi et al., 2018). As ovalbumin is a major protein in egg whites, the replacement of ovalbumin with a therapeutic gene offers considerable promise for the high scale production of foreign proteins, similar to that seen in mammalian bioreactors. Ever since the anticoagulant anti-thrombin $\left(\operatorname{Atryn}^{\mathbb{R}}\right)$, expressed as a component of transgenic goat's milk, was first approved for human use, the search has been on to identify and develop other animal bioreactor systems. Among the potential models, chicken eggs represent one of the most promising animal bioreactor candidates due to the high capacity of egg production in combination with a favorable safety profile.
Excessive body fat is a significant cause of health and production problems in industrial chicken production. Leg weakness is commonly observed in fat broiler chickens, along with other problems, such as reduced reproductive performance in the breeding stock. Similarly, the type of fat deposited in the carcass can vary between individuals and may lead to adverse health outcomes for consumers (Park et al., 2019). To reduce fat deposition, Park et al. (2019) generated a G0/G1 switch gene 2 (GOS2) knockout chicken using the CRISPR/Cas9 method (Park et al., 2019). G0S2 was firstly identified as a key regulator in cell cycling (Siderovski et al., 1990); however, it is now known that GOS2 plays a critical role in the regulation of lipid metabolism (Yang et al., 2010; Heckmann et al., 2014; Zhang et al., 2017; Park et al., 2019). Under normal circumstances, excessive energy is converted to lipids and accumulates as triglyceride droplets in the fat tissue of animals. When animals need more energy or are fasting, triglycerides are hydrolyzed into glycerol and fatty acids. Three different lipases (adipose triglyceride lipase, ATGL; hormone-sensitive lipase, HSL; monoacylglycerol lipase, MGL) are involved in triglyceride hydrolysis, with G0S2 regulating the critical first step in this process by inhibiting ATGL activity (Yang et al., 2010; Heckmann et al., 2014; Zhang et al., 2017; Park et al., 2019). Deletion of GOS2 in chickens removes this inhibition of ATGL activity, leading to an $\sim 50 \%$ reduction in fat deposition due to the continuous hydrolysis of triglycerides in adipose tissue. Interestingly, these GOS2 knockout chickens did not show any phenotypic differences compared to wild-type chickens (Park et al., 2019). This G0S2 knockout line is expected to offer considerable insight into the mechanisms of fat metabolism in chickens, which could be useful for industrial applications by enabling greater control of energy balance. Furthermore, these gene-tailored chickens represent a promising opportunity for the livestock industry, with approval for human consumption possible in the near future. As chickens are among the most important livestock species worldwide, the potential of CRISPR/Cas9 genome-edited chickens goes beyond basic research, with numerous agricultural and industrial applications now possible due to the lack of exogenous transgene integration issues common with other methods. 


\section{GENE-EDITING APPLICATIONS IN LIVESTOCK}

In 2015, a transgenic salmon expressing a growth hormone transgene derived from the fast-growing salmon was first approved for human consumption (Heidi, 2015). This transgenic salmon showed faster growing performance compared to wild-type salmon (Heidi, 2015). Regulatory approval of this transgenic species for human consumption served as a watershed moment for the agricultural community, opening up a new era of transgenic and genome-edited livestock, particularly for industrial applications. A summary of existing transgenic and genome-edited livestock is presented in Table 1, highlighting the large number of research articles published since the first adaptation of the CRISPR/Cas9 system to animal cells (Cong et al., 2013; Mali et al., 2013). In livestock, the genome-edited technologies are primarily being applied for improvement of growth performance, development of disease-resistant lines, and enhancement of animal welfare.

Wang et al. (2015) and Kang et al. (2017) produced two separate myostatin (also known as growth and differentiation factor 8, GDF8) gene knockout pigs using the CRISPR/Cas9 and TALEN methods, respectively (Wang et al., 2015; Kang et al., 2017). The myostatin knockout phenotype is characterized by double-muscling, a major economic trait in the livestock industry. Myostatin controls skeletal muscle homeostasis by inhibiting skeletal muscle growth; deletion of the myostatin gene removes this inhibition, leading to a more hypermuscular phenotype
(Wang et al., 2015; Kang et al., 2017). As fast growth with increased skeletal muscle mass is one of major goals in commercial pig breeding, incorporation of the myostatin knockout pig could be utilized for the rapid introgression of this useful genotype into commercial pig breeds.

Within the livestock industry, the threat of epidemic diseases capable of quickly spreading to farm animals represents an important and persistent fear. Thus, many attempts are now being conducted to prevent such pandemic diseases using genome-editing strategies. For example, it may be possible to inhibit viral infections by disrupting the cell-membrane receptor for specific viruses. Using this approach, Whitworth et al. (2016) demonstrated that gene-edited pigs could be protected from porcine reproductive and respiratory syndrome virus (PRRSV) (Whitworth et al., 2016) via the disruption of CD163, a specific receptor for entry of PRRSV into cells (Whitworth et al., 2016). After infection challenge into the CD163-edited pigs, no pathogenic and clinical signs such as fever or respiratory signs were observed (Whitworth et al., 2016). Furthermore, these gene-edited pigs did not contain any exogenous transgenes in their genome (Whitworth et al., 2016).

Another major cause of epidemic viral infection is African swine fever (ASF) which present worldwide (Palgrave et al., 2011; Lillico et al, 2016). ASF virus is a highly virulent disease of domestic pigs; however, other porcine species, such as the warthog, are resistant to ASF (Palgrave et al., 2011; Lillico et al, 2016). Palgrave et al. (2011) reported on the variation in RELA ( $p 65, v$-rel reticuloendo-

Table 1. The summary of the transgenic and genome-edited livestock

\begin{tabular}{llll}
\hline Species & \multicolumn{1}{c}{ Technical platforms } & \multicolumn{1}{c}{ Purpose } & Current status \\
\hline Goat & Transgenic & Production of anticoagulant anti-thrombin (Atryn ${ }^{\circledR}$ ) from transgenic goat & USA FDA approval \\
Salmon & Transgenic & Transgenic salmon with growth hormone gene of fast-growing salmon & USA FDA approval \\
Rabbit & Transgenic & Production of human C1 esterase inhibitor from transgenic rabbit & USA FDA approval \\
Chicken & Transgenic & Production of sebelipase $\alpha$ from transgenic hen's egg & USA FDA approval \\
Chicken & Gene-editing (TALEN) & Production of ovalbumin gene-knockout chicken & Park et al., 2014 \\
Chicken & Gene-editing (CRISPR-Cas9) & Production of immunoglobulin gene-knockout chicken & Dimitrov et al., 2016 \\
Pig & Gene-editing (TALEN, CRISPR-Cas9) & Production of myostatin gene-knockout pig & Wang et al., 2015; \\
& & & \\
Pig & Gene-editing (CRISPR-Cas9) & Replacement with African swine fever virus-resistant genotype et al., 2017 & Lillico et al., 2016 \\
Pig & Gene-editing (CRISPR-Cas9) & Production of CD163 gene-knockout pig (resistant to PRRSV) & Whitworth et al., 2016 \\
Cattle & Gene-editing (TALEN) & Production of hornless cattle with POLLED gene & Carlson et al., 2016 \\
Chicken & Gene-editing (CRISPR-Cas9) & Production of ovomucoid gene-knockout chicken & Oishi et al., 2016 \\
Chicken & Gene-editing (CRISPR-Cas9) & Production of human INF-beta from transgenic hen's egg & Oishi et al., 2018 \\
Chicken & Gene-editing (CRISPR-Cas9) & Production of G0S2 gene-knockout chicken & Park et al., 2019 \\
\hline
\end{tabular}


theliosis viral oncogene homolog A) identified between the warthog and domestic pig and suggested that the introduction of the warthog RELA genotype into commercial pigs could be used to induce viral tolerance and prevent rapid death upon ASFV infection (Lillico et al., 2016). Lillico et al. (2016) subsequently generated commercial pigs with the warthog RELA genotype mediated by ZFN (Lillico et al., 2016).

Another application of genome-editing tools could be to improve animal welfare. To protect cattle or dairy producers from accidental injury, the physical dehorning in young calves is a standard farm management practice. However, the dehorning process is not only costly but is also a painful mutilation for the cattle (Carlson et al., 2016). Genetic studies have identified variants associated with hornlessness (also known as polled) in cattle in which the hornless phenotypic trait generally is common in beef but rare in dairy breeds. Carlson et al. (2017) generated hornless dairy cattle by introgression of POLLED using the TALEN platform (Carlson et al., 2016). Taken together, the specifically-targeted genome engineering tools described here offer significant advantages in genome editing with respect to livestock breeding. Based on known genetic variations and natural mutations, the conventional breeding programs for the genomic selection have consistently improved the economic traits. These genome editing technologies could be used to further streamline breeding strategies for the selection and creation of more productive, healthier, and environment-adapted farm animals.

\section{CONFLICTS OF INTEREST}

No potential conflict of interest relevant to this article was reported.

\section{ACKNOWLEDGEMENTS}

This work was carried out with the support of "Cooperative Research Program for Agriculture Science \& Technology Development (Project No. PJ0133482018)" Rural Development Administration and also supported by Korea Institute of Planning and Evaluation for Technology in Food, Agriculture, Forestry and Fisheries (IPET) through Agri-Bio Industry Technology Development Program, funded by Ministry of Agriculture, Food and Rural Affairs (MAFRA) (316005-5).

\section{ORCID}

Tae Sub Park: https://orcid.org/0000-0002-0372-5467

\section{REFERENCES}

Carlson DF, Lancto CA, Zang B, Kim ES, Walton M, Oldeschulte D, Seabury C, Sonstegard TS and Fahrenkrug SC. 2016. Production of hornless dairy cattle from genome-edited cell lines. Nat. Biotechnol. 34:479-81.

Cong LF, Ran A, Cox D, Lin S, Barretto R, Habib N, Hsu PD, Wu X, Jiang W, Marraffini LA and Zhang F. 2013. Multiplex genome engineering using CRISPR/Cas systems. Science. 339:81923.

Dimitrov L, Pedersen D, Ching KH, Yi H, Collarini EJ, Izquierdo S, van de Lavoir MC and Leighton PA. 2016. Germline Gene Editing in Chickens by Efficient CRISPR-Mediated Homologous Recombination in Primordial Germ Cells. PLoS One. 11:e0154303.

Harvey AJ, Speksnijder G, Baugh LR, Morris JA and Ivarie R. 2002. Expression of exogenous protein in the egg white of transgenic chickens. Nat. Biotechnol. 20:396-99.

Heckmann BL, Zhang X, Xie X, Saarinen A, Lu X, Yang X and Liu J. 2014. Defective adipose lipolysis and altered global energy metabolism in mice with adipose overexpression of the lipolytic inhibitor G0/G1 switch gene 2 (G0S2). J. Biol. Chem. 289:1905-16.

Heidi Ledford. 2015. Transgenic salmon leaps to the dinner table. Nature. 527:417-8

Kamihira M, Ono K, Esaka K, Nishijima K, Kigaku R, Komatsu H, Yamashita T, Kyogoku K and Iijima S. 2005. High-level expression of single-chain Fv-Fc fusion protein in serum and egg white of genetically manipulated chickens by using a retroviral vector. J. Virol. 79:10864-74.

Koller BH, Hagemann LJ, Doetschman T, Hagaman JR, Huang S, Williams PJ, First NL, Maeda N and Smithies O. 1989. Germline transmission of a planned alteration made in a hypoxanthine phosphoribosyltransferase gene by homologous recombination in embryonic stem cells. Proc. Natl. Acad. Sci. USA. 86:8927-31.

Lillico SG, Proudfoot C, King TJ, Tan W, Zhang L, Mardjuki R, Paschon DE, Rebar EJ, Urnov FD, Mileham AJ, McLaren DG and Whitelaw CB. 2016. Mammalian interspecies substitution of immune modulatory alleles by genome editing. Sci. Rep. 6:21645.

Lillico SG, Sherman A, McGrew MJ, Robertson CD, Smith J, Haslam C, Barnard P, Radcliffe PA, Mitrophanous KA, Elliot EA and Sang HM. 2007. Oviduct-specific expression of two therapeutic proteins in transgenic hens. Proc. Natl. Acad. Sci. USA. 104:1771-6.

Mali P, Yang L, Esvelt KM, Aach J, Guell M, DiCarlo JE, Norville JE and Church, GM. 2013. RNA-guided human genome engineering via Cas9. Science. 339:823-6.

McGrew MJ, Sherman A, Ellard FM, Lillico SG, Gilhooley HJ, 
Kingsman AJ, Mitrophanous KA and Sang H. 2004. Efficient production of germline transgenic chickens using lentiviral vectors. EMBO Rep. 5:728-33.

Oishi I, Yoshii K, Miyahara D, Kagami H and Tagami T. 2016. Targeted mutagenesis in chicken using CRISPR/Cas9 system. Sci. Rep. 6:23980.

Oishi I, Yoshii K, Miyahara D and Tagami T. 2018. Efficient production of human interferon beta in the white of eggs from ovalbumin gene-targeted hens. Sci. Rep. 8:10203.

Palgrave CJ, Gilmour L, Lowden CS, Lillico SG, Mellencamp MA and Whitelaw CB. 2011. Species-specific variation in RELA underlies differences in NF- $\kappa \mathrm{B}$ activity: a potential role in African swine fever pathogenesis. J. Virol. 85:6008-14.

Palmiter RD, Norstedt G, Gelinas RE, Hammer RE and Brinster RL. 1983. Metallothionein-human GH fusion genes stimulate growth of mice. Science. 222:809-14.

Park TS and Han JY. 2012. piggyBac transposition into primordial germ cells is an efficient tool for transgenesis in chickens. Proc. Natl. Acad. Sci. USA. 109:9337-41.

Park TS, Lee HJ, Kim KH, Kim JS and Han JY. 2014. Targeted gene knockout in chickens mediated by TALENs. Proc. Natl. Acad. Sci. USA 111:12716-21.

Park TS, Park J, Lee JH, Park JW and Park BC. 2019. Disruption of G0/G1 switch gene 2 (G0S2) reduced abdominal fat deposition and altered fatty acid composition in chicken. FASEB J. 33:1188-98.

Schusser B, Collarini EJ, Yi H, Izquierdo SM, Fesler J, Pedersen
D, Klasing KC, Kaspers B, Harriman WD, van de Lavoir MC, Etches RJ and Leighton PA. 2013. Immunoglobulin knockout chickens via efficient homologous recombination in primordial germ cells. Proc. Natl. Acad. Sci. USA. 110:201705.

Scott BB and Lois C. 2006. Generation of transgenic birds with replication-deficient lentiviruses. Nat. Protoc. 1:1406-11.

Siderovski DP, Blum S, Forsdyke RE and Forsdyke DR. 1990. A set of human putative lymphocyte G0/G1 switch genes includes genes homologous to rodent cytokine and zinc finger protein-encoding genes. DNA Cell Biol. 9:579-587.

Thompson S, Clarke AR, Pow AM, Hooper ML and Melton DW. 1989. Germ line transmission and expression of a corrected HPRT gene produced by gene targeting in embryonic stem cells. Cell. 56:313-21.

Whitworth KM, Rowland RR, Ewen CL, Trible BR, Kerrigan MA, Cino-Ozuna AG, Samuel MS, Lightner JE, McLaren DG, Mileham AJ, Wells KD and Prather RS. 2016. Gene-edited pigs are protected from porcine reproductive and respiratory syndrome virus. Nat. Biotechnol. 34:20-2.

Yang X, Lu X, Lombès M, Rha GB, Chi YI, Guerin TM, Smart EJ and Liu J. 2010. The G(0)/G(1) switch gene 2 regulates adipose lipolysis through association with adipose triglyceride lipase. Cell Metab. 11:194-205.

Zhang X, Heckmann BL, Campbell LE and Liu J. 2017. G0S2: A small giant controller of lipolysis and adipose-liver fatty acid flux. Biochim. Biophys. Acta. 1862:1146-54. 